\title{
The combined effect of two mutations that alter serially homologous color pattern elements on the fore and hindwings of a butterfly
}

\author{
Antónia Monteiro*1,2,3, Bin Chen ${ }^{1}$, Lauren C Scott ${ }^{1}$, Lindsey Vedder ${ }^{1}, \mathrm{H}$ \\ Joop Prijs ${ }^{2}$, Alan Belicha-Villanueva ${ }^{1}$ and Paul M Brakefield ${ }^{2}$
}

Address: ${ }^{1}$ Department of Biological Sciences, University at Buffalo, 109 Cooke Hall, Buffalo, NY 14228, USA, ${ }^{2}$ Section of Evolutionary Biology, Institute of Biology, Leiden University, P.O. Box 9516, 2300 RA Leiden, The Netherlands and ${ }^{3}$ Department of Ecology and Evolutionary Biology, Yale University, P.O. Box 208106, New Haven, CT 06520-8106, USA

Email: Antónia Monteiro* - antonia.monteiro@yale.edu; Bin Chen - bin.chen@yale.edu; Lauren C Scott - lcscott@acsu.buffalo.edu; Lindsey Vedder - lcvedder@uab.edu; H Joop Prijs - H.J.prijs@biol.rug.nl; Alan Belicha-Villanueva - a.belicha@gmail.com;

Paul M Brakefield - p.m.brakefield@biology.leidenuniv.nl

* Corresponding author

Published: II May 2007

BMC Genetics 2007, 8:22 doi:10.1186/147/-2156-8-22
Received: 15 December 2006

Accepted: II May 2007

This article is available from: http://www.biomedcentral.com/I47I-2156/8/22

(c) 2007 Monteiro et al; licensee BioMed Central Ltd.

This is an Open Access article distributed under the terms of the Creative Commons Attribution License (http://creativecommons.org/licenses/by/2.0), which permits unrestricted use, distribution, and reproduction in any medium, provided the original work is properly cited.

\begin{abstract}
Background: The ability for serially homologous structures to acquire a separate identity has been primarily investigated for structures dependent on Hox gene input but is still incompletely understood in other systems. The fore and hindwings of butterflies are serially homologous structures as are the serially homologous eyespots that can decorate each of these wings. Eyespots can vary in number between fore and hindwings of the same individual and mutations of large effect can control the total number of eyespots that each of the wings displays. Here we investigate the genetics of a new spontaneous color pattern mutation, Missing, that alters eyespot number in the nymphalid butterfly, Bicyclus anynana. We further test the interaction of Missing with a previously described mutation, Spotty, describe the developmental stage affected by Missing, and test whether Missing is a mutant variant of the gene Distal-less via a linkage association study.

Results: Missing removes or greatly reduces the size of two of the hindwing eyespots from the row of seven eyespots, with no detectable effect on the rest of the wing pattern. Offspring carrying a single Missing allele display intermediate sized eyespots at these positions. Spotty has the opposite effect of Missing, i.e., it introduces two extra eyespots in homologous wing positions to those affected by Missing, but on the forewing. When Missing is combined with Spotty the size of the two forewing eyespots decreases but the size of the hindwing spots stays the same, suggesting that these two mutations have a combined effect on the forewing such that Missing reduces eyespot size when in the presence of a Spotty mutant allele, but that Spotty has no effect on the hindwing. Missing prevents the complete differentiation of two of the eyespot foci on the hindwing. We found no evidence for any linkage between the Distal-less and Missing genes.

Conclusion: The spontaneous mutation Missing controls the differentiation of the signaling centers of a subset of the serial homologous eyespots present on both the fore and the hindwing in a dose-dependent fashion. The effect of Missing on the forewing, however, is only observed when the mutation Spotty introduces additional eyespots on this wing. Spotty, on the other hand, controls the differentiation of eyespot centers only on the forewing. Spotty, unlike Missing, may be under Ubx gene regulation, since it affects a subset of eyespots on only one of the serially homologous wings.
\end{abstract}




\section{Background}

Modularity of body plans, and of serially repeated structures is widespread in the animal kingdom [1]. Examples of modular structures include vertebrae [2], teeth [3], limbs [4], digits [5], arthropod body segments [6], C. elegans terminal rays [7], insect fore and hindwings [8-10], and butterfly eyespot patterns [11-13]. One of the key questions driving research in the field of modularity is to understand how such modules acquire the ability to differentiate into more or less distinct structures [14-16]. This differentiation and specialization of repeated body parts has, in the case of arthropod's body segments, increased through evolutionary time [17] presumably facilitating the radiation of these organisms into different environments.

The two pairs of wings on a butterfly are serially repeated structures, as are several of the pattern elements present within each wing [18]. Pattern elements such as eyespots, for instance, can occur in each of the wing subdivisions, the wing cells, delineated by veins. Nijhout [18] proposed that the diversity of butterfly color patterns seen today results from the presence or absence, or through the modification of the size, shape, color or position of these serially homologous pattern elements within each wing cell. While the Hox gene, Ultrabithorax (Ubx), appears to be responsible for allowing the hindwing to acquire different wing patterns from the forewing [8], the genes and mechanisms by which particular serially homologous elements within each wing can acquire a separate identity from the other elements, however, are still unknown. Here we analyze the phenotypic effects of two spontaneous mutations, Missing and Spotty that affect the development of two serially homologous eyespots independently of the remaining eyespots on the wings.

The nymphalid butterfly Bicyclus anynana normally displays two marginal eyespots on both the dorsal and ventral sides of the forewing and seven eyespots on the ventral hindwing. Spontaneous $[19,20]$ and X-ray induced mutations [12] can alter the number of eyespots that appear on the wings surfaces, producing substantial departures from the wild type pattern. The spontaneous mutation Spotty was previously shown to be a single segregating factor of codominant effect [21]. Spotty homozygotes have two extra eyespots on both the ventral and dorsal surfaces on the forewings of $B$. anynana. These extra eyespots occur in wing cells between those carrying the wildtype anterior and posterior eyespots. Spotty heterozygotes have either reduced sizes for both extra eyespots, or have one of the eyespots missing and the other eyespot present but reduced in size. This mutation, despite only having been analyzed in a qualitative fashion, appears to show a very localized effect in controlling the eyespot developmental program in a subset of the wing cells. Miss- ing is a new spontaneous mutation that has a very similar phenotype to another $x$-ray induced mutation, $3+4$, previously described [12]. Contrary to Spotty, this mutation removes two eyespots from the hindwing, but the wing cells affected by Missing are homologous to those affected by Spotty on the forewing.

Here we investigate the phenotypic effects of Missing when crossed with either Missing, wildtype, or Spotty in order to describe the mutation in homozygote and in heterozygote condition and also to investigate whether Missing and Spotty, which when in isolation only seem to affect the hindwing or forewing pattern, respectively, show any interaction when placed together in the same individual. We additionally test whether during the imaginal disc stage the Distal-less and Engrailed transcription factors are absent from the centers of the hindwing eyespots that don't develop in adults of the Missing stock. We select one of these genes, Distal-less, as a possible target of the Missing mutation, and test whether this candidate gene is associated to the Missing phenotype by means of a linkage association study.

\section{Results}

\section{Extreme missing individuals have low fitness}

Missing individuals show considerable variation in their phenotype, even after intensive selection for a pure homozygote stock. This variation is represented by the presence of very small dots marking the center of the hindwing eyespots, in wing cells 3 and 4 , in a large proportion of the individuals. For our crosses we selected mostly extreme looking individuals, but sometimes included individuals that displayed a differentiated but tiny eyespot pupil, and sometimes a very narrow gold ring. When no black scales were visible, but a pupil was clearly differentiated, the diameter of the eyespot was given as the diameter of the white pupil. We observed that families whose parents had an extreme "Missing" phenotype produced few offspring, compared to families where the average size of eyespots 3 and 4 in the parents was less extreme (Figure 1). After surveying the distribution of eyespot sizes in the offspring we decided that some of the putative "Missing × Missing" crosses were probably crosses between Missing/Missing and Missing/Wildtype heterozygotes and excluded them from future comparisons. In practice, this meant that we applied a threshold of 0.3 $\mathrm{mm}$ to the maximal size that each of the two hindwing eyespots can display in order for that individual to be called a Missing phenotype. It is also likely that other modifier loci are contributing to additional variation in the size of the eyespots targeted by Missing and possibly also contributing to variation in fitness. 


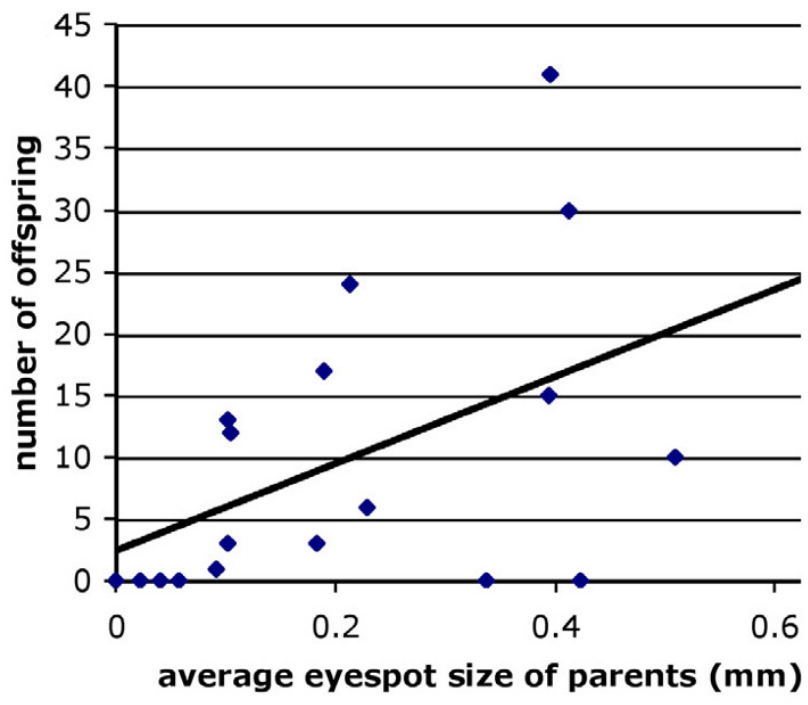

Figure I

Extreme Missing individuals have fewer offspring. Relationship between the average size of eyespots 3 and 4 in parents carrying absent or very small eyespots at these positions, and the number of offspring produced. The proportion of variation explained by the regression line $\left(R^{2}\right)$ is 0.24 and its slope is significantly different form zero $(P=0.028)$.

\section{The effect of Missing on the hindwing}

Crosses of Missing with Missing (Figure 2) produced offspring that displayed some variation in their hindwing phenotype, but overall displayed reduced or absent eyespots at positions 3 and 4 . Hybrids resulting from crosses of Missing with Wildtype produced intermediate sized eyespots 3 and 4 relative to those from Wildtype*Wildtype and Missing $\times$ Missing eyespots (Figure 2). Analysis of variance for the size of each of the hindwing eyespots among the three types of cross mentioned above showed that the effect of Missing is localized to positions 3 and 4 on the hindwing (Table 1). Sex and family are also factors that explain a significant proportion of the variance in the data (Table 1). This mutation has a codominant effect relative to Wildtype as well as a localized effect on the hindwing.

When Missing/Wildtype individuals were backcrossed to Missing there appeared to be a bi-modal distribution of phenotypes, especially pronounced in one of the largest families (Figure 3, F52). There appears to be, however, fewer offspring under the first peak of the bi-modal distributions. This may relate to the fact that several extreme Missing/Missing genotypes may have not survived to adulthood. In all, these results suggest that the Missing mutation(s) is likely segregating at a single major genetic locus.

\section{The effect of Spotty on the forewing}

The effect of the Spotty mutation on the forewing was previously described by Brakefield and French [21], who concluded that this mutant had a codominant effect relative to Wildtype. Spotty homozygotes display two well-developed eyespots in positions 3 and 4 on the forewing, and heterozygotes display two intermediate sized eyespots at these positions, or sometimes a single smaller eyespot at either position 3 or position 4 .

\section{The effect of Missing on the forewing}

Wildtype individuals normally do not display eyespots in positions 3 and 4 on the forewing (not shown). Missing*Missing and Missing*Wildtype crosses also did not display eyespots at these positions (Fig. 4).

\section{The effect of Spotty on the hindwing}

The size of the hindwing eyespots between offspring of Spotty $\times$ Wildtype versus offspring from Wildtype*Wildtype crosses (Fig. 2) are not significantly different for any of the eyespots (Table 2), indicating that Spotty only affects the number and size of eyespots located on the forewing.

\section{The combined effects of Spotty and Missing on the forewing and on the hindwing}

Crosses of homozygous Missing with homozygous Spotty showed that these mutations interact and display an addi-

Table I: The effect of Missing on the hindwing.

\begin{tabular}{|c|c|c|c|c|c|c|c|}
\hline & $\mathbf{n}$ & Cross type $(\mathrm{df}=2)$ & $\mathbf{p}$ & Sex $(d f=I)$ & $\mathbf{p}$ & Family $(\mathrm{df}=19)$ & $\mathbf{p}$ \\
\hline hw eye I & 731 & 1.512 & 0.246 & 23.339 & 0.000 & 15.194 & 0.000 \\
\hline hw eye 2 & 730 & 1.960 & 0.168 & 18.430 & 0.000 & 14.342 & 0.000 \\
\hline hw eye 3 & 731 & 25.766 & 0.000 & 6.749 & 0.010 & 15.455 & 0.000 \\
\hline hw eye 4 & 731 & 47.945 & 0.000 & 47.604 & 0.000 & 12.604 & 0.000 \\
\hline hw eye 5 & 730 & 2.306 & 0.127 & $|78.78|$ & 0.000 & 18.563 & 0.000 \\
\hline hw eye 6 & 727 & 3.151 & 0.066 & 289.971 & 0.000 & $\mid 8.311$ & 0.000 \\
\hline hw eye 7 & 721 & 0.722 & 0.499 & 170.101 & 0.000 & 16.700 & 0.000 \\
\hline
\end{tabular}

F-values and probabilities from an analysis of variance to explore whether there is a difference in hindwing eyespot size among three types of cross: Wild type $\times$ Wild type, Wild type $\times$ Missing and Missing $\times$ Missing. Sex and Family (random factor nested within cross-type) were used as additional factors. Only main effects for factors were calculated. 


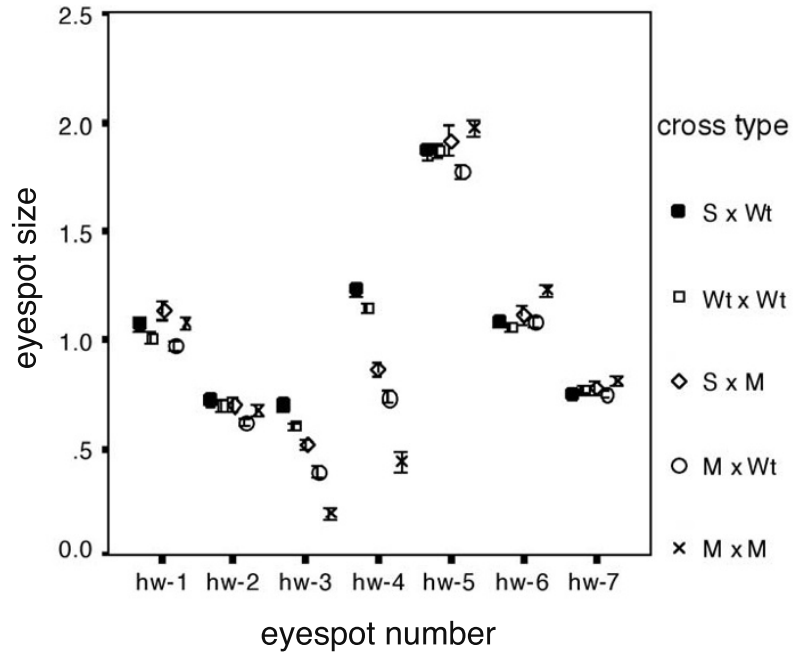

Figure 2

The effect of Missing is restricted to two of the hindwing eyespots. Average eyespot size for each of the seven eyespots on the hindwing for five different set of crosses (sexes and families combined). Spotty $\times$ Wildtype (filled circle), Wildtype $\times$ Wildtype (square), Spotty $\times$ Missing (bullseye), Missing $\times$ Wildtype (empty circle), and Missing $\times$ Missing (cross). Error bars represent $95 \%$ confidence intervals for the mean.

tive effect on the forewing but not on the hindwing. When Missing is combined with Spotty, the previously undetected effect of Missing on the forewing (see above) becomes visible in the Spotty heterozygote background. Forewing eyespots 3 and 4 are smaller in Missing $\times$ Spotty offspring relative to Wildtype $\times$ Spotty offspring (Figure 4 ; Table 3 ). There was no difference in the size of the flanking eyespots (eyespots 2 and 5) in these two types of cross (Table 3). These results indicate that Missing has the effect of reducing the size of eyespots 3 and 4 on both hindwings and forewings.

When the effect of Spotty was analyzed on the hindwing, by comparing eyespot sizes from Spotty $\times$ Missing versus Wildtype $\times$ Missing offspring (Figure 2), there was no significant effect of cross-type detected for any of the eyespots (Table 4). To be able to have more power in detecting the effect of Spotty on the hindwing, we also investigated whether the effect of the Spotty allele, in Spotty $\times$ Wildtype and Spotty $\times$ Missing offspring combined, resulted in larger hindwing eyespot sizes relative to the Wildtype allele in Wildtype $\times$ Wildtype, or Wildtype $\times$ Missing offspring combined. Despite the larger sample size ( $\mathrm{n}=803)$, there was still no detectable significant effect of Spotty in increasing hindwing eyespot size (data not shown).

\section{Immunohistochemistry}

Late larval hindwing discs of individuals taken from the Missing stock displayed a range of Distal-less and engrailed expression patterns in the $3^{\text {rd }}$ and $4^{\text {th }}$ wing cells, from the absence of both these proteins in the future eyespot centers (Figure 5), to the presence of small differentiated foci, expressing both proteins (not shown). The expression of Distal-less along the intervenous stripes was present in all hindwing cells.
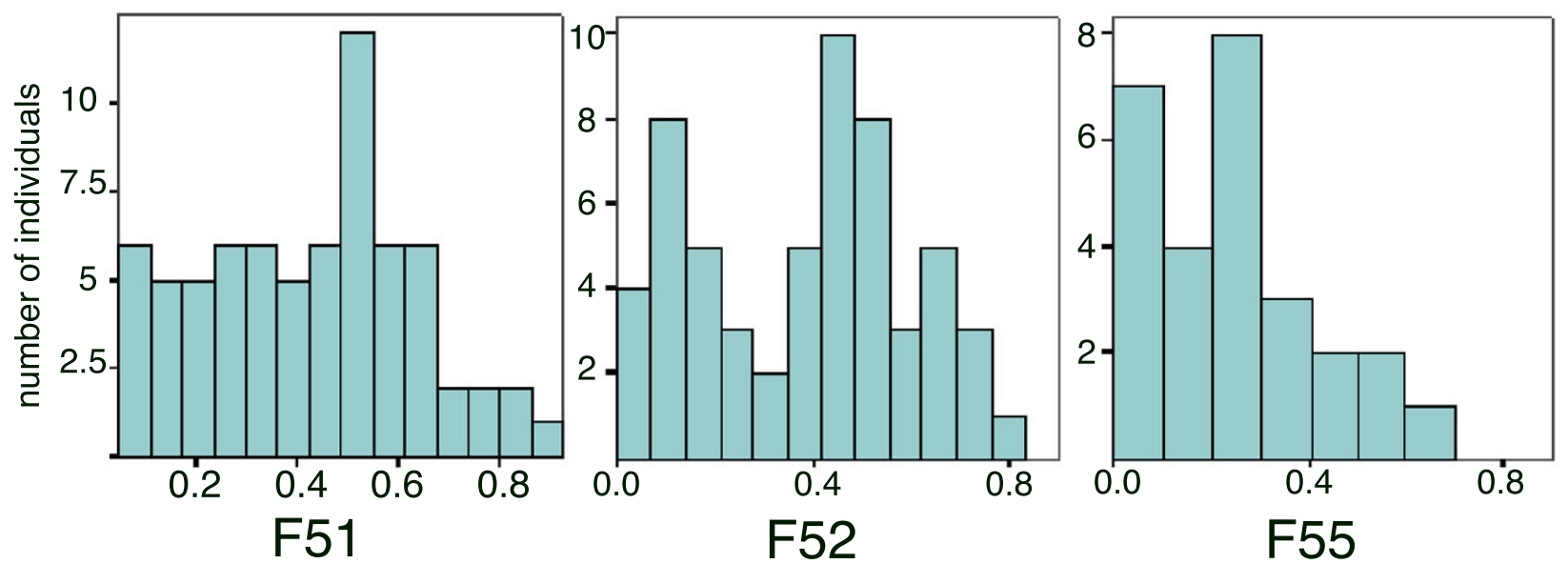

Figure 3

Backcross distribution plots. The distribution of average eyespot sizes for eyespots 3 and 4 for offspring from the three back-crosses of Wiltype/Missing $\times$ Missing (Families F5I, F52, and F55). Error bars represent $95 \% \mathrm{Cl}$ for the means. 


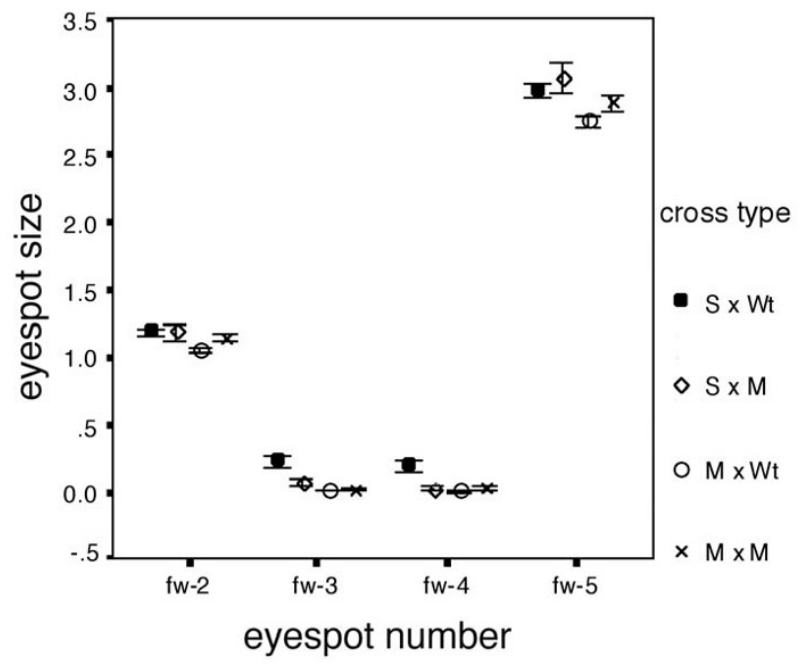

Figure 4

Missing also reduces the size of forewing eyespots. Average eyespot size for each of the four eyespots on the forewing for four different set of crosses (sexes and families combined): Spotty $\times$ Wildtype (filled circle), Spotty $\times$ Missing (bullseye), Missing $\times$ Wildtype (empty circle), and Missing $\times$ Missing (cross). Error bars represent $95 \%$ confidence intervals for the mean.

\section{Association study}

We identified an informative SNP (C/A) in a recognition sequence for the BseNI restriction enzyme (NCCAGT) in the Dll 5'UTR fragment analyzed for the four grandparents. The wildtype grandparent was homozygous CCCAGT and the BseNI enzyme cut the amplified PCR fragment into two fragments, $451 \mathrm{bp}$ and $239 \mathrm{bp}$ long, respectively. The Missing grandparent was homozygous CCAAGT and thus was not cut by the BseNI enzyme. The F1 male parent was an expected heterozygote (CCCAGT/ CCAAGT) and had the expected heterozygote restriction pattern; whereas the Missing female that was crossed with the F1 male had a similar genotype as the Missing grandmother, and was not cut by the restriction enzyme.

We tested two hypotheses: 1) If the Dll polymorphism is linked to the Missing mutation then we expect to find the majority of backcross individuals with the smallest or with absent eyespots to be homozygote for the CCAAGT genotype and display the "no-cut" pattern; and the majority of the individuals with the largest eyespots to display the "heterozygote-cut" restriction pattern on the gel. 2) On the other hand if the Dll polymorphism is not linked to the Missing mutation then we expect approximately $50 \%$ of backcross individuals with the smallest eyespots to have the "no-cut" pattern, and 50\% to have the "heterozygote-cut" pattern. The same frequencies will be expected for the individuals with the largest eyespots.

From the 15 individuals that were genotyped with the smallest eyespots $(0.06 \mathrm{~mm}$ average diameter $\pm 0.02 \mathrm{~mm}$ SE) we obtained 7 individuals ( 2 females and 5 males) that were not cut by the enzyme, and 8 individuals ( 4 females and 4 males) that were cut by the enzyme. From the 15 individuals that were genotyped with the largest eyespots $(0.51 \mathrm{~mm}$ average diameter $\pm 0.03 \mathrm{~mm} \mathrm{SE}), 10$ individuals ( 2 females and 8 males) were not cut by the enzyme, and 5 individuals ( 3 females and 2 males) were cut by the enzyme. These results clearly support the hypothesis of no linkage between Dll and Missing genes.

\section{Discussion}

The series of crosses clearly show that Missing, is a co-dominant mutation that has the dramatic effect of removing or reducing the size of two eyespots on the hindwing when in homozygote and heterozygote condition, respectively. Missing has the additional effect of reducing the size of the eyespots present in a homologous position on the forewing. The subtle effect of the Missing mutation on the forewing is not easily observed by eye and was only borne out because of the detailed quantitative approach used here. Spotty, on the other hand, is a mutation that intro-

Table 2: The effect of Spotty on the hindwing.

\begin{tabular}{|c|c|c|c|c|c|c|c|}
\hline & $\mathbf{n}$ & Cross type $(\mathrm{df}=\mathrm{I})$ & $\mathbf{P}$ & $\operatorname{Sex}(d f=I)$ & $\mathbf{p}$ & Family $(\mathrm{df}=8)$ & $\mathbf{p}$ \\
\hline hw eye I & 505 & 0.633 & 0.449 & 9.478 & 0.002 & 25.289 & 0.000 \\
\hline hw eye 2 & 505 & 0.053 & 0.823 & 5.785 & 0.017 & 35.354 & 0.000 \\
\hline hw eye 3 & 505 & 4.056 & 0.078 & 19.695 & 0.000 & 19.433 & 0.000 \\
\hline hw eye 4 & 505 & 1.028 & 0.340 & 51.158 & 0.000 & 16.781 & 0.000 \\
\hline hw eye 5 & 505 & 0.156 & 0.704 & 135.204 & 0.000 & 43.546 & 0.000 \\
\hline hw eye 6 & 505 & 0.001 & 0.978 & 206.472 & 0.000 & 38.923 & 0.000 \\
\hline hw eye 7 & 505 & 0.274 & 0.615 & 117.239 & 0.000 & 38.247 & 0.000 \\
\hline
\end{tabular}

F-values and probabilities from an analysis of variance to explore whether there is a difference in hindwing eyespot size between two types of cross: Spotty $\times$ Wild type, and Wild type $\times$ Wildtype. See additional info in legend of Table I. 
Table 3: The effect of Missing on the forewing in a Spotty background.

\begin{tabular}{|c|c|c|c|c|c|c|c|}
\hline & $\mathbf{n}$ & Cross type $(\mathrm{df}=\mathrm{I})$ & $\mathbf{P}$ & $\operatorname{Sex}(d f=I)$ & $\mathbf{p}$ & Family (df = 6) & $\mathbf{p}$ \\
\hline fw eye 2 & 259 & 0.042 & 0.844 & 19.956 & 0.000 & 27.303 & 0.000 \\
\hline fw eye 3 & 259 & 5.773 & 0.042 & 26.794 & 0.000 & 3.272 & 0.004 \\
\hline fw eye 4 & 260 & 10.664 & 0.009 & 38.542 & 0.000 & 2.172 & 0.046 \\
\hline fw eye 5 & 261 & 0.218 & 0.656 & 505.787 & 0.000 & 23.066 & 0.000 \\
\hline
\end{tabular}

F-values and probabilities from an analysis of variance to explore whether there is a difference in forewing eyespot sizes between two types of cross: Spotty $\times$ Wild type, and Spotty $\times$ Missing. See additional info in legend of Table I.

duces two eyespots on the forewing, and has no effect on the size of the homologous eyespots on the hindwing.

Selector genes such as Ubx, that are expressed only on the hindwings of insects, including butterflies, have been shown to affect the size of eyespots on the hindwing relative to their homologous counterparts on the forewing [8][22]. Ubx-dependent eyespot size changes in the butterfly Junonia (Precis) coenia involve quantitative changes both in the signaling component as well as in the response components of the eyespot differentiation mechanism [8]. From our analysis it appears that the qualitative effect of the Spotty allele on eyespot number is also regulated in a Hox gene-dependent fashion. Spotty is selectively expressed in the forewing, but not in the hindwing, indicating that a putative hindwing repressor (such as Ubx) modulates the effect of this allele. On the other hand, the Missing allele appears to exert its action on the eyespot developmental program in a Ubx gene-independent fashion. Missing will affect the size of homologous eyespots in both forewing and hindwings simultaneously.

It still remains to be determined whether these two mutations are genetically linked, perhaps representing alleles of the same gene. Crosses performed between Missing and Spotty individuals, followed by backcrosses to Missing, Wildype, or Spotty, were performed in order to try and analyze the shape of the backcross distributions. The shape of these distributions would indicate the likely link- age status of the Missing and Spotty genes. If the distributions had a clear two-peaked shape, this would indicate likely linkage, and the presence of two main genotypic classes $(M / S$ and $M / M$ for backcrosses to Missing for instance). If, on the other hand, the distributions were more normally distributed, i.e, reflecting the sum of four normal distributions, each representing a genotypic class, centered around different mean values $(M / M,+/+; M / M$, $S /+;+M,+/+$; and $+/ M, S /+)$, then this would indicate that Missing and Spotty were found either on different linkage groups, or in the same linkage group but far apart. Unfortunately, there were two major complications to the successful completion of these analyses. First, the backcross distribution of Missing/Spotty hybrids crossed to Missing produced a skewed distribution against the zero eyespot diameter along the $\mathrm{x}$-axis, where a series of Missing-like individuals were clustered. These skewed distributions cannot be readily analyzed with standard mixture models. Second, there was a strong family effect in that while some families produced a strong two-peaked distribution, other families didn't.

The immunohistochemistry showed that the Missing mutation, similarly to the $3+4$ mutation previously described [12], affects the complete differentiation of the group of signaling cells at the center of the future eyespots. The focal cells, marked by the domains of Dll and en expression, are either a small cluster or do not differentiate at all, and as a result, there is no signaling during the

Table 4: The effect of Spotty on the hindwing in a Missing background.

\begin{tabular}{|c|c|c|c|c|c|c|c|}
\hline & $\mathbf{n}$ & Cross type $(\mathrm{df}=\mathrm{I})$ & $\mathbf{p}$ & $\operatorname{Sex}(d f=I)$ & $\mathbf{p}$ & Family $(\mathrm{df}=8)$ & $\mathbf{p}$ \\
\hline hw eye I & 298 & 3.834 & 0.095 & 23.124 & 0.000 & 26.999 & 0.000 \\
\hline hw eye 2 & 298 & 2.360 & 0.171 & 16.580 & 0.000 & 16.060 & 0.000 \\
\hline hw eye 3 & 298 & 1.804 & 0.225 & 5.395 & 0.021 & 22.767 & 0.000 \\
\hline hw eye 4 & 298 & 1.749 & 0.230 & 55.719 & 0.000 & 14.663 & 0.000 \\
\hline hw eye 5 & 298 & 1.623 & 0.246 & 121.377 & 0.000 & 16.063 & 0.000 \\
\hline hw eye 6 & 298 & 0.160 & 0.701 & 81.218 & 0.000 & 10.900 & 0.000 \\
\hline hw eye 7 & 297 & 0.350 & 0.574 & 41.664 & 0.000 & 16.560 & 0.000 \\
\hline
\end{tabular}

F-values and probabilities from an analysis of variance to explore whether there is a difference in hindwing eyespot size between two types of cross: Missing $\times$ Wild type, and Missing $\times$ Spotty. See additional info in legend of Table I. 


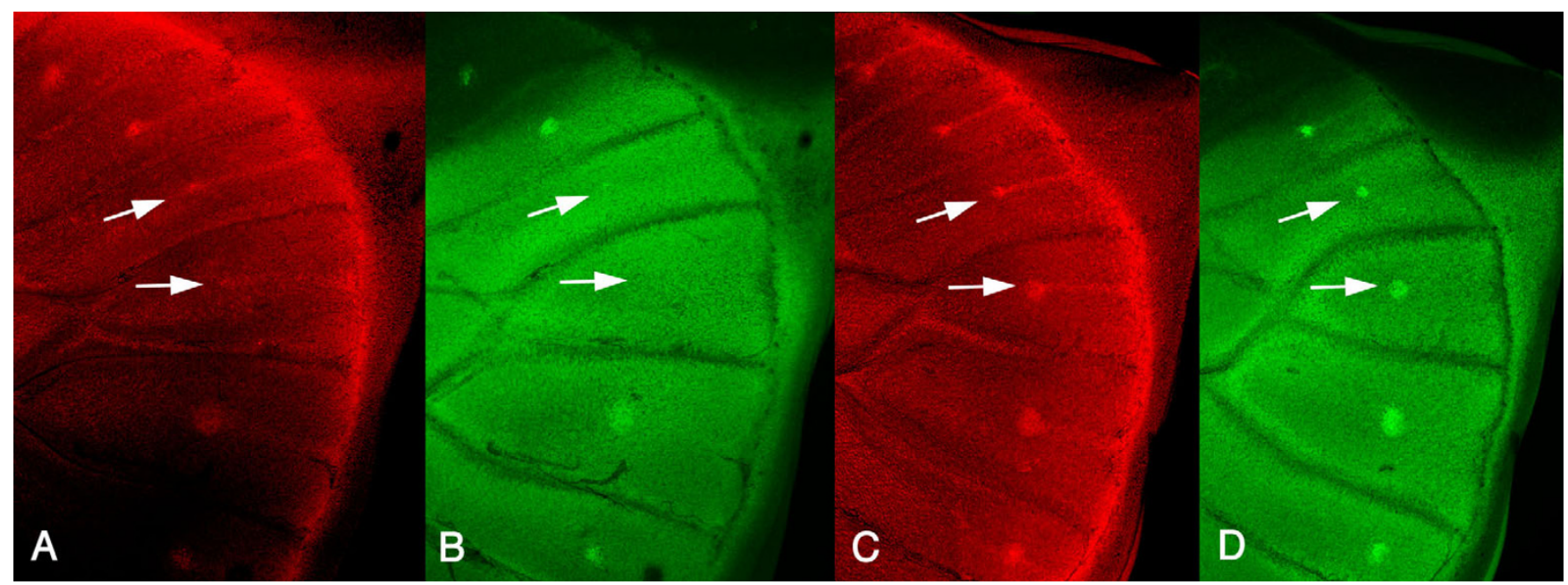

Figure 5

Distal-less and Engrailed are expressed at low levels in two of the hindwing eyespot centers in Missing. Distalless (red) and Engrailed (green) immunolocalizations in late fifth instar larval wing discs of a Missing and a Wildtype individual. A, B) Missing individual showing very low levels of DIl and En in the eyespot foci of wing cells 3 and 4 (arrows); C, D) Wildtype individual showing normal levels of DII and En protein levels in the foci.

pupal stage of eyespot differentiation, no visible white pupil, and no color rings of scales on the adult wing.

Distal-less is known to be one of the first genes to be expressed in the eyespot pupils during the fifth instar larval wing disc stage [23-25]. In Drosophila, this gene is also the first gene to be expressed in the future position of the ventral appendages of the fly. It acts as a selector gene that works in a fairly context-independent fashion since its ectopic activation in the leg disk of Drosophila results in a complete leg duplication [26]. Because of these similarities we decided to test whether a putative mutation in the regulatory region of this gene may be causing the Missing phenotype. The association study concluded that the Missing mutation is not linked to Distal-less. Alternative genes to test would include Notch, also shown to be expressed in the larval wing disc, in the eyespot foci, and recently shown to be expressed slightly earlier in development in these cells relative to Distal-less [23], or other genes involved in the focus differentiation pathway, but putatively already acting downstream of Dll and Notch (reviewed in [20,27]). Given that we are looking for a single gene mutation, a more sensible approach to identify this gene in the future may be to take a positional mapping study, with markers positioned all along the genome, until a candidate genomic regions is found to be associated with the mutation. Progress in the development of genomic tools for Bicyclus may allow this to be done in the near future [28].

\section{Conclusion}

We described the phenotypic effects of two mutations that affect the development of two of the serial homologous eyespots present in both fore and hindwings of $B$. anynana. Both mutations have a co-dominant effect relative to their wild-type alleles. These mutations, however, differ in the way that they interact with putative selector genes, previously shown to influence both the signal and the response components of the eyespot developmental mechanism in homologous eyespots positioned either on the fore or on the hindwings. Spotty targets eyespots only on the forewing and, therefore, may be under Ubx gene regulation, whereas Missing has a Ubx-gene independent effect, and reduces the size of eyespots on both fore and hindwing. Both these mutation are acting quite early in the eyespot development pathway by affecting the differentiation of the central group of cells, the focus, responsible for early pupal signaling and differentiation of the concentric rings of colored scales in an eyespot [29,30].

These two mutations highlight the ability of genes of large effect to affect subsets of serially homologous structures and give them a separate identity from the rest. It is still unclear, however, whether the ancestral condition for these serial homologues is that of separately controlled units, regulated by genes such as Spotty and Missing that have very discrete affects on eyespot development brought together to form a complete row of eyespots, or whether, on the other hand, eyespots appeared as a cohesive unit of 
Table 5: Summary of all the crosses performed between Spotty (S), Missing (M), and Wildtype (Wt) individuals.

\begin{tabular}{|c|c|c|}
\hline Crosses & Family & \# of offspring \\
\hline \multicolumn{3}{|l|}{ Spotty (male) crosses: } \\
\hline$S$ male $(\operatorname{PmABC} 2) \times W t$ female $(\mathrm{PfA} 2)$ & $\mathrm{A} 2$ & 53 \\
\hline S male $(\operatorname{PmABC} 3) \times W t$ female (PfA3) & $\mathrm{A} 3$ & 33 \\
\hline S male $(\mathrm{PmABC7}) \times \mathrm{W}$ t female $(\mathrm{PfB} 7)$ & B7 & 20 \\
\hline S-Wt hybrid male $(\mathrm{PmB72}) \times \mathrm{Wt}$ female $(\mathrm{Pf72})$ & B72 & 68 \\
\hline S-Wt hybrid male $(\mathrm{PmB73}) \times \mathrm{M}$ female $(\mathrm{PfB} 73)$ & B73 & 45 \\
\hline \multicolumn{3}{|l|}{ Wild type (male) crosses: } \\
\hline Wt male $(\mathrm{PmDE} 2) \times \mathrm{S}$ female $(\mathrm{PfD} 2)$ & D2 & 44 \\
\hline Wt male $(\mathrm{PmDE} 3) \times \mathrm{S}$ female $(\mathrm{PfD} 3)$ & D3 & 34 \\
\hline Wt male $(\mathrm{PmDE} 3) \times \mathrm{M}$ female $(\mathrm{PfE} 3)$ & E3 & 25 \\
\hline$W t$ male $\times W t$ female & $16^{*}$ & 84 \\
\hline$W_{t}$ male $\times W t$ female & $17^{*}$ & 35 \\
\hline $\mathrm{Wt}$ male $\times \mathrm{Wt}$ female & $19 *$ & 76 \\
\hline$W t$ male $\times W t$ female & $20 *$ & 62 \\
\hline Wt male $\times$ Wt female & $5 I^{*}$ & 64 \\
\hline \multicolumn{3}{|l|}{ Missing (male) crosses } \\
\hline M male $(\mathrm{Pml}) \times \mathrm{M}$ female $(\mathrm{Pfl})$ & I & 10 \\
\hline M male $(\mathrm{Pm} 4) \times \mathrm{M}$ female $(\mathrm{Pf} 4)$ & 4 & 5 \\
\hline M male $(\operatorname{Pm} 6) \times M$ female $(\mathrm{Pf} 6)$ & 6 & 41 \\
\hline M male $(\mathrm{Pm} 7) \times \mathrm{M}$ female $(\mathrm{Pf7})$ & 7 & 13 \\
\hline M male $(P m I I) \times M$ female $(P f l I)$ & 11 & 3 \\
\hline M male $(\operatorname{Pm} / 4) \times$ M female $(\mathrm{Pfl} / 4)$ & 14 & 15 \\
\hline M male $(P m \mid 5) \times M$ female $(P f \mid 5)$ & 15 & 24 \\
\hline M male $(\operatorname{Pm} \mid 6) \times$ M female $(\mathrm{Pfl6})$ & 16 & 13 \\
\hline M male $(\operatorname{Pm} \mid 8) \times$ M female $(\mathrm{Pf} \mid 8)$ & 18 & 17 \\
\hline M male $(\mathrm{Pm} 20) \times \mathrm{M}$ female $(\mathrm{Pf20})$ & 20 & 12 \\
\hline M male $(\mathrm{Pm} 2 \mathrm{I}) \times \mathrm{M}$ female $(\mathrm{Pf} 2 \mathrm{I})$ & 21 & 6 \\
\hline M male $(\operatorname{Pm} 22) \times$ M female $(P f 22)$ & 22 & 30 \\
\hline M male $(\mathrm{PmFGH} 2) \times \mathrm{Wt}$ female $(\mathrm{PfF} 2)$ & $\mathrm{F} 2$ & 73 \\
\hline M male $(\mathrm{PmFGH} 3) \times \mathrm{Wt}$ female $(\mathrm{PfF} 3)$ & F3 & 28 \\
\hline M male $(\mathrm{PmFGH} 4) \times \mathrm{Wt}$ female $(\mathrm{PfF} 4)$ & $\mathrm{F} 4$ & 49 \\
\hline M male $(\mathrm{PmFGH} 5) \times \mathrm{Wt}$ female $(\mathrm{PfF5})$ & F5 & 46 \\
\hline M-Wt hybrid male $(\mathrm{PmF5} \mathrm{I}) \times \mathrm{M}$ female $(\mathrm{PfF5} \mathrm{I})$ & F5I & 70 \\
\hline M-Wt hybrid male (PmF52) $\times$ M female (PfF52) & $\mathrm{F} 52$ & 58 \\
\hline M-Wt hybrid male $($ PmF55) $\times$ M female (PfF55) & F55 & 27 \\
\hline M male $(\mathrm{PmFGH} 2) \times \mathrm{S}$ female $(\mathrm{PfG} 2)$ & G2 & 25 \\
\hline M male $(\mathrm{PmFGH} 3) \times \mathrm{S}$ female $(\mathrm{PfG} 3)$ & G3 & 8 \\
\hline M male $(\mathrm{PmFGH} 5) \times \mathrm{S}$ female $(\mathrm{PfG} 5)$ & G5 & 44 \\
\hline M-S hybrid male $(P m G 27) \times W t$ female $(P f G 27)$ & G27 & 52 \\
\hline M-S hybrid male $(\operatorname{PmG} 28) \times W t$ female $(\operatorname{PfG} 28)$ & $\mathrm{G} 28$ & 60 \\
\hline M-S hybrid male $(P m G 5 I) \times W t$ female $(P f G 5 I)$ & G5I & 129 \\
\hline M-S hybrid male $(\mathrm{PmG} 56) \times \mathrm{Wt}$ female $(\mathrm{PfG} 56)$ & G56 & 84 \\
\hline M-S hybrid male $(P m G 59) \times W t$ female $($ PfG59) & G59 & 99 \\
\hline M-S hybrid male $(\mathrm{PmG} 5 \mathrm{II}) \times \mathrm{Wt}$ female $(\mathrm{PfG} 5 \mathrm{II})$ & G5II & 119 \\
\hline M-S hybrid male $(P m G \mid I 2) \times W t$ female $(P f G 5 \mid 2)$ & G512 & 48 \\
\hline
\end{tabular}


Table 5: Summary of all the crosses performed between Spotty (S), Missing (M), and Wildtype (Wt) individuals. (Continued)

\begin{tabular}{|c|c|c|}
\hline M-S hybrid male $($ PmG55) $\times$ S female $($ PfG55) & G55 & 54 \\
\hline M-S hybrid male $(\mathrm{PmG} 33) \times \mathrm{M}$ female $(\mathrm{PfG} 33)$ & G33 & 82 \\
\hline M-S hybrid male $(\mathrm{PmG} 35) \times \mathrm{M}$ female $(\mathrm{PfG} 35)$ & G35 & 27 \\
\hline M-S hybrid male $(\mathrm{PmG} 36) \times \mathrm{M}$ female $(\mathrm{PfG} 36)$ & G36 & 60 \\
\hline M-S hybrid male $(\mathrm{PmG} 53) \times \mathrm{M}$ female $(\mathrm{PfG} 53)$ & G53 & 91 \\
\hline M-S hybrid male $(\mathrm{PmG54}) \times$ M female $(\mathrm{PfG} 54)$ & G54 & 83 \\
\hline M-S hybrid male $(P m G 57) \times$ M female $($ PfG57) & G57 & $14 \mid$ \\
\hline M-S hybrid male $(\mathrm{PmG} 58) \times \mathrm{M}$ female $(\mathrm{PfG} 58)$ & G58 & 141 \\
\hline M-S hybrid male $(\operatorname{PmG} 5 \mathrm{I}) \times \mathrm{M}$ female $(\mathrm{PfG} 5 \mathrm{I})$ & G513 & 43 \\
\hline M-S hybrid male $(P m G 5 \mid 4) \times$ M female $(P f G 5 \mid 4)$ & $\mathrm{G} 514$ & 73 \\
\hline M-S hybrid male $(\operatorname{PmG} 5 \mathrm{I5}) \times \mathrm{M}$ female $(\mathrm{PfG} \mid 5)$ & GI5I & 89 \\
\hline
\end{tabular}

(* data from Monteiro et al. 2003).

similarly looking structures, one per wing cell, resembling the proposed Nymphalid Groundplan [13], that gradually gained separate regulatory control by the appearance of genes such as Spotty and Missing. Phylogenetic comparative methods may eventually be able to shed light on this question.

\section{Methods \\ Crosses}

We reared a series of single pair families by placing virgin adult butterflies in small cubic net hanging cages and followed the crossing scheme outlined in Table 5. In addition, we used data from previously reared single pair crosses of wildtype with wildtype [12], reared in the same climate room and in identical conditions to the new crosses described here. Adults were reared on banana, eggs were collected on young maize plants, and larvae from each family were reared in tube-like net cages on maize plants. All animals were reared inside a climate room at $27^{\circ} \mathrm{C}, 12 \mathrm{~h}: 12 \mathrm{~h}$ light:dark photoperiod and $80 \%$ relative humidity. Upon emergence the ventral wing pattern of $\mathrm{F} 1$ individuals was photographed with a black and white video camera and images were saved as Tiff files.

The ventral pattern of forewings and hindwings was quantified by measuring the diameter of the black discs of all eyespots present on the ventral side of fore and hindwings along an axis parallel to the wing veins. Diameter measurements were done using the Tiff files in Object Image 1.62 [31]. Data were later transferred to MS Excel version $\mathrm{X}$.

\section{Statistics}

Analyses of variance for eyespot size were performed by asking whether there was a significant size difference for any of the forewing or hindwing eyespots (analyzed individually) between offspring from different types of cross (Missing $\times$ Wildtype, Wildtype $\times$ Wildtype, etc). Cross type was used as a fixed factor. For all analyses sex was also used as a fixed factor, since males are usually smaller than females and also have smaller eyespots, and family was coded as a random factor, nested within cross type. Analyses were done using SPSS version 11 for the Macintosh. Regression analyses were done in Excel version X for the Macintosh. Graphics were done is SPSS and in Excel.

\section{Immunohistochemistry}

Late fifth instar larval wings of Missing individuals were stained according to the protocol described in [32] with antibodies targeting Distal-less (a gift from Grace Boekhoff-Falk [33]) and Engrailed (antibody 4F11, a gift from Nipam Patel [34]).

\section{Association study}

An additional cross was performed between a Wildtype male and a Missing female, followed by a backcross of a single F1 male offspring to another Missing female. The bodies of these individuals were separated from the wings, placed in $2 \mathrm{ml}$ screw cap vials filled with $100 \%$ ethanol, and stored at $-70^{\circ} \mathrm{C}$. Hindwings for all the backcross progeny were photographed, and the diameter of eyespots at positions 3 and 4 was measured and averaged for each individual. DNA was extracted from the four parents, and a 690 bp 5'UTR fragment, from the previously cloned Distal-less $(\mathrm{Dll})$ gene [35] was amplified with the following two primers: Dll-NF1 (5'-CGCGAGTTGGTTGTGTCGGGTTACCTCGGA-3') and Dll-R6 (5'-CGTGGAAACACAGCATCACTATCACA-3'). PCR amplification conditions were $5 \mathrm{~min}$ at $94^{\circ}$, followed by 35 cycles of $40 \mathrm{sec}$ at $94^{\circ} \mathrm{C}, 40 \mathrm{sec}$ at $57^{\circ} \mathrm{C}$, and $60 \mathrm{sec}$ at $72^{\circ} \mathrm{C}$. The amplification ended with a 5 min final extension period at $72^{\circ} \mathrm{C}$. The PCR product was inserted into pGEM-T vector (Promega) and cloned in E. coli JM109 cells. Five clones were sequenced from each of the four parents and the sequences were screened for the presence of an informative polymorphic marker, i.e, a marker with two alleles and with a different allele, ideally in homozygote condition, present in the Missing and Wildtype 
grandparents. This marker should also be easily genotyped by means of an enzymatic essay where homozygote and heterozygote individuals can be differentiated by their restriction-digest banding pattern. The backcross generation was genotyped by first extracting DNA from the most extreme 15 individuals from each of the two ends of the eyespot size distribution. The same Dll fragment was amplified via PCR from these individuals, purified using a Quiagen PCR purification column, and then digested overnight with BseNI (BsrI) restriction enzyme following the manufacture's directions (Fermentas). Digested DNA was run on a $1.5 \%$ agarose gel, photographed, and the genotype was assayed from the restriction pattern.

\section{Authors' contributions}

AM designed and coordinated the experiments, helped rear the butterflies, collected the immunohistochemistry data, analyzed the eyespot size data, and wrote the manuscript. BC, assisted by LV, performed the Dll association study, LS scanned all the wings, performed all the eyespot measurements, and assisted AM in the eyespot size analyses, JP did most of the butterfly rearing, $\mathrm{AB}$ prepared the butterfly wings for imaging and the bodies for DNA analysis, and PMB helped design the experiments and critically revised the final manuscript.

\section{Acknowledgements}

We thank Daniel Gaile for statistical advice; Els Schlattman, Bert de Winter, Niels Wurzer, and Dennis Pietras for plant husbandry; Nipam Patel and Grace Boekhoff-Falk for the anti-En and anti-DII antibodies, respectively; Human Frontier Science Program award RG0058 for financial support to $A M$ and HJP; and NSF award IBN-03I6283 for financial support to BC, LCS, $L V$, and $A B V$.

\section{References}

I. Schlosser G, Wagner GP: Modularity in Development and Evolution. Chicago, University of Chicago Press; 2004:600.

2. Carapuco M, Novoa A, Bobola N, Mallo M: Hox genes specify vertebral types in the presomitic mesoderm. Gene Dev Gene Dev 2005, 19:2||6-2|2|.

3. Stock DW: The genetic basis of modularity in the development and evolution of the vertebrate dentition. 200I, 356: $1633-1653$.

4. Young NM, Hallgrimsson B: Serial homology and the evolution of mammalian limb covariation structure. 2005, 59:269|-2704.

5. Galis F, Kundrat M, Metz JAJ: Hox genes, digit identities and the theropod/bird transition. J Exp Zool Part B J Exp Zool Part B 2005, 304B:198-205.

6. Akam M: Hox genes, homeosis and the evolution of segment identity: no need for hopeless monsters. Int J Dev Biol 1998, 42:445-45I.

7. Lints R, Jia L, Kim K, Li C, Emmons SW: Axial patterning of C-elegans male sensilla identities by selector genes. 2004, 269:|37-I5I.

8. Weatherbee SD, Nijhout HF, Grunert LW, Halder G, Galant R, Selegue J, Carroll S: Ultrabithorax function in butterfly wings and the evolution of insect wing patterns. 1999, 9:109-II5.

9. Tomoyasu $Y$, Wheeler SR, Denell RE: Ultrabithorax is required for membranous wing identity in the beetle Tribolium castaneum. 2005, 433:643-647.
10. Carroll SB, Weatherbee SD, Langeland JA: Homeotic Genes and the Regulation and Evolution of Insect Wing Number. 1995, 375:58-6I.

II. Beldade P, Koops K, Brakefield PM: Modularity, individuality, and evo-devo in butterfly wings. PNAS 2002.

12. Monteiro A, Prijs J, Bax M, Hakkaart T, Brakefield PM: Mutants highlight the modular control of butterfly eyespot patterns. Evol Dev 2003, 5: $180-187$.

13. Nijhout HF: Elements of butterfly wing patterns. J Exp Zool 200I, 29 I:2I 3-225

14. Winther RG: Varieties of modules: Kinds, levels, origins, and behaviors. 2001, 29I:II6-129.

15. Margulies EH, Kardia SLR, Innis JW: A comparative molecular analysis of developing mouse forelimbs and hindlimbs using Serial Analysis of Gene Expression (SAGE). Genome Research 200I, II:I686-1698.

16. Weatherbee SD, Halder G, Kim J, Hudson A, Carroll S: Ultrabithorax regulates genes at several levels of the wing-patterning hierarchy to shape the development of the Drosophila haltere. Gene Dev Gene Dev 1998, I 2:1474- 4882.

17. McShea DW: Metazoan complexity and evolution: Is there a trend? Perspective. Evolution 1996, 50:477-492.

18. Nijhout HF: The development and evolution of butterfly wing patterns. Washington, Smithsonian Institution Press; 1991:297.

19. Beldade P, Brakefield PM: The genetics and evo devo of butterfly wing patterns. Nat Rev Genet 2002, 3:442-452.

20. McMillan WO, Monteiro A, Kapan DD: Development and evolution on the wing. Trends Ecol Evol 2002, 17:125-133.

21. Brakefield PM, French V: Butterfly wing patterns: Developmental mechanisms and evolutionary change. Acta Biotheor 1993, $41: 447-468$.

22. Weatherbee SD, Carroll SB: Selector genes and limb identity in arthropods and vertebrates. Cell 1999, 97:283-286.

23. Reed RD, Serfas MS: Butterfly wing pattern evolution is associated with changes in a Notch/Distal-less temporal pattern formation process. Curr Biol 2004, I 4: I I59-II66.

24. Carroll SB, Gates J, Keys DN, Paddock SW, Panganiban GEF, Selegue JE, Williams JA: Pattern formation and eyespot determination in butterfly wings. Science 1994, 265:109-1 I4.

25. Brakefield PM, Gates J, Keys D, Kesbeke F, Wijngaarden PJ, Monteiro A, French V, Carroll SB: Development, plasticity and evolution of butterfly eyespot patterns. Nature 1996, 384:236-242.

26. Gorfinkiel N, Morata G, Guerrero I: The homeobox gene Distalless induces ventral appendage development in Drosophila. Genes Dev 1997, II:2259-227I.

27. Evans TM, Marcus JM: A simulation study of the genetic regulatory hierarchy for butterfly eyespot focus determination. Evol Dev 2006, 8:273-283.

28. Beldade P, Brakefield PM, Long AD: Generating phenotypic variation: prospects from "evo-devo" research on Bicyclus anynana wing patterns. Evol Dev 2005, 7:101-107.

29. French $V$, Brakefield PM: Eyespot development on butterfly wings: The focal signal. Dev Biol 1995, 168: | | 2-123.

30. Monteiro A, Glaser G, Stockslagger S, Glansdorp N, Ramos DM: Comparative insights into questions of lepidopteran wing pattern homology. BMC Developmental Biology 2006, 6:52.

31. Vischer NOE, Huls PG, Woldringh CL: Object-Image: An interactive image analysis program using structured point collection. Binary (Bioline) 1994, 6:.

32. Brunetti CR, Selegue JE, Monteiro A, French V, Brakefield PM, Carroll SB: The generation and diversification of butterfly eyespot color patterns. Curr Biol 200I, I I:I578-I585.

33. Panganiban G, Sebring A, Nagy L, Carroll S: The development of crustacean limbs and the evolution of arthropods. Science 1995, 270:1363-1366.

34. Patel NH, Martin-Blanco E, Coleman KG, Poole SJ, Ellis MC, Kornberg TB, Goodman CS: Expression of engrailed proteins in Arthropods, Annelids, and Chordates. Cell 1989, 58:955-968.

35. Beldade P, Brakefield PM, Long AD: Contribution of Distal-less to quantitative variation in butterfly eyespots. Nature 2002, 415:315-317. 